\title{
Risk factors for acute hepatitis B and its progression to chronic hepatitis in Shanghai, China
}

\author{
H W Zhang, ${ }^{1} \mathrm{~J} H$ Yin, ${ }^{1}$ Y T Li, ${ }^{2}$ C Z Li, ${ }^{3}$ H Ren, ${ }^{2}$ C Y Gu, ${ }^{1}$ H Y Wu, ${ }^{2}$ X S Liang, ${ }^{3}$ P Zhang, \\ J F Zhao, ${ }^{1}$ X J Tan, ${ }^{1}$ W Lu, ${ }^{1}$ S Schaefer, ${ }^{4}$ G W Cao ${ }^{1}$
}

${ }^{1}$ Department of Epidemiology, Second Military Medical University, Shanghai, China;

${ }^{2}$ Department of Acute Infectious Diseases, Center for Disease

Control and Prevention, Shanghai, China; ${ }^{3}$ Department of Infectious Diseases, The $1^{\text {st }}$ Affiliated Hospital, Second Military Medical University, Shanghai, China; ${ }^{4}$ Abteilung für Virologie, Universität Rostock, Germany

Correspondence to:

Professor G W Cao, Department of Epidemiology, Second Military Medical University, 800 Xiangyin Road, Shanghai 200433, China; gcao@smmu.edu.cn or guangwencao@yahoo.com

H-W Z and J-H Y contributed equally to this work.

Revised 30 July 2008 Accepted 5 August 2008 Published Online First 28 August 2008

\author{
ABSTRACT \\ Background and aims: The major risk factors for acute \\ hepatitis $B(A H B)$ in China and the viral factors \\ determining the progression from acute to chronic \\ hepatitis B remain largely unknown.
}

Methods: Epidemiological studies within a populationbased surveillance for AHB in adults were performed in Shanghai, China, including 294 patients, 588 matched controls and 572 family members of the patients.

Results: Invasive medical procedures, household contact with hepatitis B virus (HBV) carriers, body care and beauty treatments, and lack of HBV vaccination were independently associated with AHB. Among those risks, pedicure in bath centres emerged. Sixty-eight of 128 patients with $\mathrm{AHB}$ were genotyped including 33 with HBV B2 and 35 with HBV C2. Twenty-five (8.50\%) of the 294 patients, including 20 with HBV C2 and 5 with HBV B2 $(p=0.013)$, progressed to chronic infection. Multivariate analysis showed that HBV C2 was independently associated with chronicification of AHB. Patients with HBV B2 were younger and there was a higher proportion of women than those with HBV C2. The prevalence of HBV B2 was higher in the patients than in neighbourhood chronic carriers. The chronic carriers with HBV B2 showed higher viral loads, higher hepatitis B e antigen (HBeAg) seropositivity, and with higher proportion in men than those with HBV C2, implying that sexual contact plays a role in the transmission of HBV B2. Phylogenetic analysis showed that HBV C2 was frequently involved in transmissions within households.

Conclusions: Despite lower viral load and HBeAg status in the chronic carriers, HBV C2 was more prone to causing chronic infection than was HBV B2.

Infection with hepatitis B virus (HBV) is a major global health problem. Approximately 3 billion people have been exposed to HBV, and more than 300 million are chronically infected with HBV. ${ }^{12}$ In $\mathrm{HBV}$ non-endemic areas, most HBV infections are transmitted during adolescence or adulthood: sexual intercourse, use of injectable drugs, and nosocomial infection are risk factors for acute hepatitis $\mathrm{B}$ (AHB). ${ }^{3-5}$ Approximately $45 \%$ of the world's population lives in regions where HBV infection is endemic. ${ }^{2}$ In the endemic areas, HBV infections frequently occur in the neonatal period or during early childhood, but very few studies on risk factors for AHB in adults have been reported.

In mainland China, an endemic area with onethird of the world's HBV carriers, HBV transmission in the neonatal period used to be a major route. ${ }^{6}$ After nationwide HBV vaccination in newborns was implemented in 1992, the prevalence of $\mathrm{HBV}$ in children decreased dramatically. A nationwide survey in 2006 showed that the prevalence of hepatitis B surface antigen (HBsAg) was around $1.5 \%$ in children under the age of 8 years, and $7.18 \%$ in the nationwide population at an age between 1 and 59 years (unpublished data). In Shanghai, the annual incidence of $\mathrm{AHB}$ has been documented since 1993 (fig 1). Although an overall decrease is evident, the incidence of AHB remains high.

The natural course of HBV infection is very distinct. An important step in the natural course of HBV infection is the transition from acute to chronic infection. Induction of HBV chronicity has been shown to be influenced by the immune system and other host factors. ${ }^{78}$ While newborns become chronic HBV carriers at a very high rate (about 90\%), immune competent adults are generally described as developing chronic hepatitis at a rate of $5-10 \% .^{1}$ The natural course of HBV infection and the response to therapy are affected by HBV genotype. $^{9-11}$ To date, eight genotypes $(\mathrm{A}-\mathrm{H})$ that differ by $8-15 \%$ at the nucleotide level have been identified. ${ }^{12}{ }^{13} \mathrm{HBV}$ genotypes show distinct geographic prevalence. ${ }^{12-14}$ In Shanghai and surrounding areas, HBV genotypes C2 (62.1-72.9\%) and B2 (13.4-28.0\%) were the most prevalent genotypes in asymptomatic HBsAg carriers (ASCs), the patients with chronic hepatitis $B$ and those with hepatocellular carcinoma. ${ }^{15}$ A contribution of viral genotypes to the persistence of $\mathrm{HBV}$ was suggested. ${ }^{16}$ However, no epidemiological study with a sufficient number of cases has shown an effect of HBV genotypes on the rate of HBV chronicity. In a limited number of cases, it was shown that HBV genotype D was associated with acute liver damage, while genotype A was associated with chronic outcome. ${ }^{17} 18$

A study for the establishment of HBV infection in chimpanzees showed that dose-dependent experimental infection led to different outcomes. ${ }^{19}$ In a woodchuck model, high doses of woodchuck hepatitis virus induced high rates of chronicity, while chronicity rates were decreased for low doses of viral infection. ${ }^{20}$ In experimental studies conducted in the 1950s, patients who developed chronic hepatitis B had higher peak levels of viral markers that appeared early during the acute phase of infection than those with self-limited hepatitis. ${ }^{21}$ These observations imply that another potential viral determinant for the chronic outcome of $\mathrm{AHB}$ is the infection dose influenced by exposure type.

To elucidate the influence of HBV genotypes on the chronic progression of $\mathrm{AHB}$, current risk factors for $\mathrm{AHB}$, and its potential impact on the
This paper is freely availa online under the BMJ Journa unlocked scheme, see http./ gut.bmj.com/info/unlocked.dt 


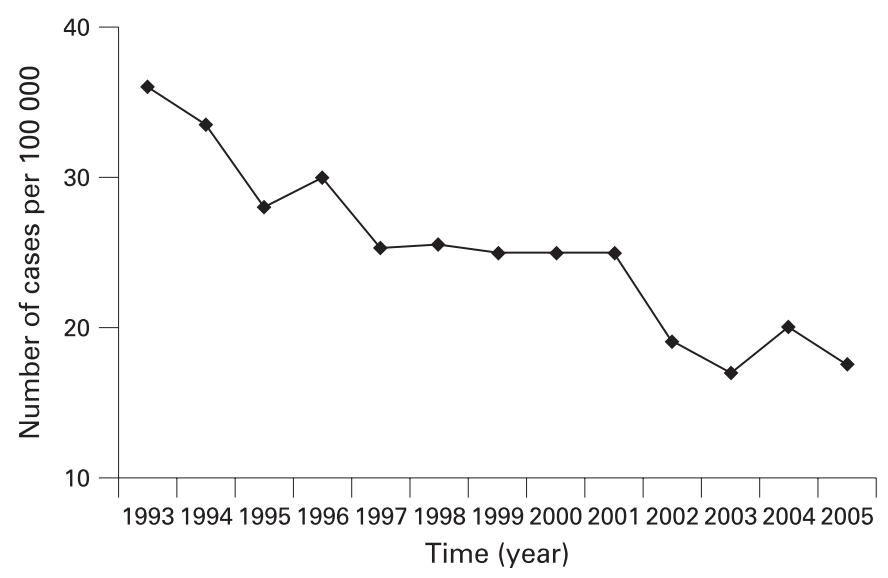

Figure 1 Annual incidence of reported cases of acute hepatitis B in Shanghai, China from 1993 to 2005 . Approximately 17.78 million people were surveyed.

disease course, we conducted a community-based study in Shanghai, China.

\section{SUBJECTS AND METHODS Pilot study}

To estimate the sample size for this 1:2 case-control study, an anonymous pilot survey of selected behaviours related to the transmission of $\mathrm{HBV}$ was initially conducted in Minhang District of Shanghai. In the population surveyed, exposure ratios of intravenous injection/infusion, pedicure, and beauty treatment were $12 \%, 14 \%$ and $5 \%$, respectively. On the basis of the frequency of the exposures, an alpha level of 0.05 , a beta level of 0.10 , and crude odds ratio (OR) level of 2.5, it was calculated that sample sizes of 134 cases, 120 cases, and 275 cases were needed, respectively. In this study, 294 patients with $\mathrm{AHB}$ were estimated to provide statistically significant data.

\section{Cases and controls}

Shanghai is composed of 18 administrative districts and one affiliated county. Five administrative districts including Songjiang, Baoshan, Pudong, Minhang and Nanhui were selected as study districts by a simple stochastic sampling method. AHB was diagnosed as follows: HBsAg and antibody to hepatitis $B$ core antigen (anti-HBc) of the immunoglobulin $M$ (IgM) class, acute-onset elevation $(>45 \mathrm{U} / \mathrm{l})$ of serum alanine aminotransferase levels. To discriminate AHB by new infection from acute exacerbation of chronic infection, the absence of serum $\mathrm{HBs} \mathrm{Ag}$ and anti-HBc before admission was verified by checking medical records. Previous negative $\mathrm{HBsAg}$ and anti$\mathrm{HBc}$ status, together with the persistent presence of HBsAg in serum after an observation period of more than 6 months, was considered as progression to chronic infection. ${ }^{22}$ Patients with acute hepatitis $\mathrm{A}$, hepatitis $\mathrm{E}$, hepatitis $\mathrm{C}$ virus infection and/or co-infection, and drug- or alcohol-induced hepatitis were excluded. During January 2004 through December 2006, 298 AHB cases with medical records showing negative HBsAg were registered in the Centers of Disease Control and Prevention of five districts of Shanghai. Four of the 298 patients were excluded from the study because the controls did not match the cases.

Control subjects matched to the cases by sex and date of birth (within 2 years). A total of 624 candidate-matched controls were randomly recruited from the source population from which the cases arose at the time of AHB diagnosis. A total of 572 family members who had lived with the patient for more than 1 year were involved in the study. A total of 113 asymptomatic HBsAG carriers (ASCs) from the same source population were recruited during HBV screening, including 36 from the candidate-matched controls, 52 from the family members and 25 from the unmatched controls from the source population.

After giving written informed consent, residents who agreed to participate completed a questionnaire and provided blood samples.

\section{Epidemiological investigation}

Patients with AHB and the controls were interviewed by trained research assistants using a standard, two-page questionnaire requesting information up to 6 months before the diagnosis of AHB. Information regarding sociodemographic characteristics, immunisation history, and exposures to known and potential risk factors for HBV infection was collected retrospectively. All participants were examined for HBV serological markers, including $\mathrm{HBsAg}$, antibody to $\mathrm{HBs}$ (anti-HBs), hepatitis $\mathrm{B}$ e antigen (HBeAg), antibody to $\mathrm{HBe}$ (anti-HBe) and anti-HBc. Standard HBV vaccination with recombinant hepatitis $B$ vaccine (Dalian Hissen Bio-Pharm, Dalian, China) was provided to those without $\mathrm{HBV}$ infection.

\section{Laboratory analysis}

During the survey, $5 \mathrm{ml}$ fasting blood from all participants was collected with a vacuum blood collection tube without anticoagulant. Serum samples of AHB patients during symptomatic phase were collected from hospitals. The serum was separated by centrifugation at $4^{\circ} \mathrm{C}$ and stored in a sterile tube at $-80^{\circ} \mathrm{C}$ within $6 \mathrm{~h}$ of sample collection. Serological testing was performed as follows: $\mathrm{HBsAg}, \mathrm{HBeAg}$, anti-HBc immunoglobulin G (IgG), IgM, anti-HBs, anti-HBe, and antibodies to hepatitis $\mathrm{C}$ virus were examined by Architect-i2000 (Abbott Laboratories, North Chicago, Illinois, USA). Antibodies to hepatitis A virus and hepatitis $\mathrm{E}$ virus were examined by enzyme-linked immunosorbent assay (Abbott Laboratories).

HBV DNA was extracted from $200 \mu \mathrm{l}$ sera by using the serum viral DNA purification kit (PG Biotechnology, Shenzhen, China). Serum viral load was measured in the LightCycler (Roche, Mannheim, Germany), using the Quantitative HBV PCR Fluorogence Diagnostic Kit (PG Biotechnology, Shenzhen, China). Genotypes of HBV were determined by using a multiplex polymerase chain reaction (PCR) assay developed in our laboratory ${ }^{23}$ and confirmed by DNA sequencing.

A part of the preS and $\mathrm{S}$ gene region of HBV genome was amplified by PCR and sequenced as described previously. ${ }^{23}$ The sequences from nt. 2919 to nt. 614 (910 base pairs) were isolated and registered in GenBank with accession numbers from EU216040 to EU216057. The sequences were aligned using the BioEdit (version 7.0.0) and CLUSTAL X 1.83 algorithms with default parameters. The phylogenetic tree was constructed by using the neighbour-joining component of the MEGA 4.0 computer program. ${ }^{24}$ Bootstrap analysis with 1000 replicates was used to determine the robustness of the tree and the evolutionary relationship of HBV.

\section{Statistical analysis}

The data were entered (double entry) and analysed using the Statistical Program for Social Sciences (SPSS12.0 for Windows). The $\chi^{2}$ test was used to determine the differences in categorical 
Figure 2 CONSORT flow diagram of this study. The broken lines (- - - -) indicate the type of epidemiological studies between the two population groups. HBV, hepatitis B virus.

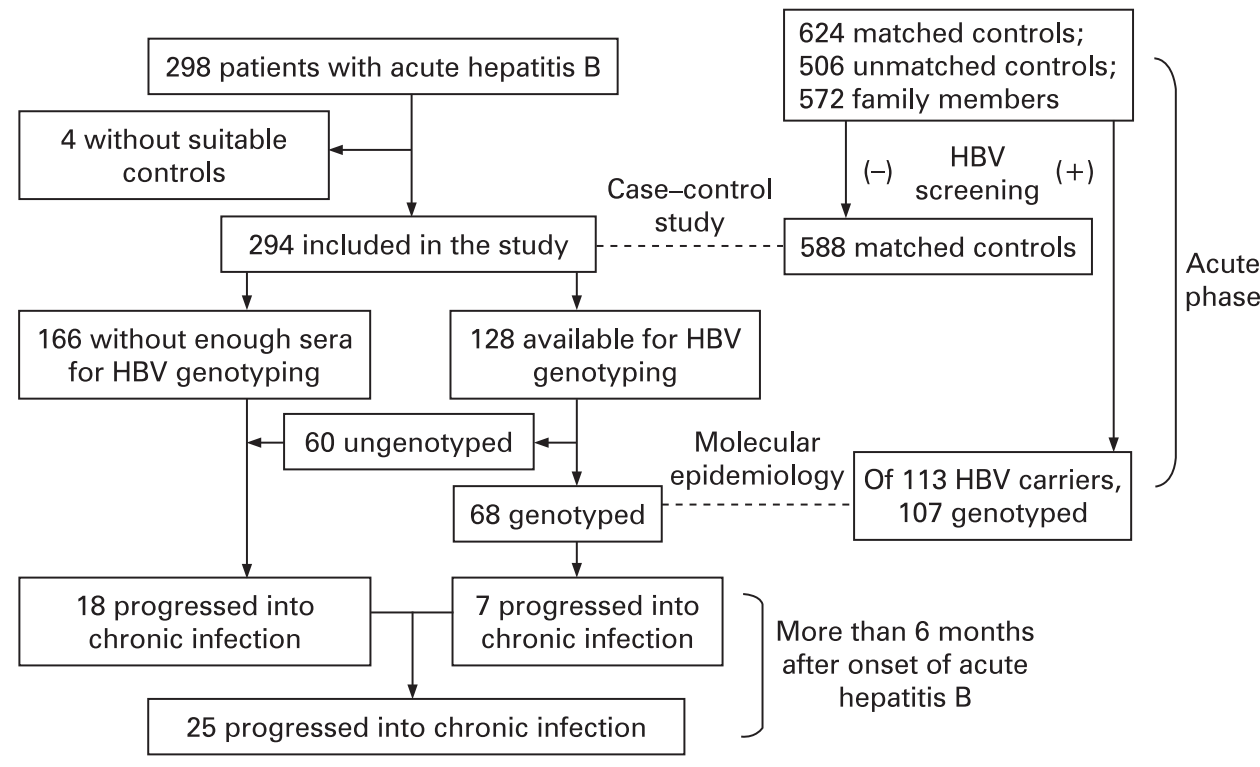

variables. The odds ratio (OR) and 95\% confidence interval (CI) for the factors under consideration were calculated in a univariate logistic regression analysis. To determine the factors contributing independently to AHB, forward stepwise multivariate regression analysis ( $p_{\text {entry }}=0.05, p_{\text {removal }}=0.10$ ) was performed. The adjusted OR (AOR) for each risk factor was estimated by the adjustments with age, sex and educational level. Univariate and multivariate analyses were used to determine the factors including HBV genotypes, age and sex associated with chronicification of AHB. Serum viral load with skewed distribution was adjusted to normal distribution by transformation into logarithmic function, and then tested by the Student $t$ test. A $p$ value $<0.05$ was considered as statistically significant.

\section{RESULTS}

\section{General information}

The mean age of the 294 patients with AHB was 41.65 (SD $12.18)$ years and the ratio of men to women was $3.28: 1$. Thirtysix $(5.77 \%)$ of the candidates matched 624 controls were

Table 1 Univariate and multivariate analyses of the risk factors exposed within 6 months before onset of acute hepatitis B: a community-based study

\begin{tabular}{|c|c|c|c|c|}
\hline Potential risk factor & Cases & Controls & OR $(95 \% \mathrm{CI})$ & AOR $(95 \% \mathrm{CI})$ \\
\hline Household contact with HBV carriers & $101(34.35)$ & $89(15.14)$ & $2.93(2.11$ to 4.08$)$ & $3.05(2.11 \text { to } 4.41)^{*}$ \\
\hline Spouse with HBV infection & $21(7.14)$ & $25(4.25)$ & $1.73(0.92$ to 3.27$)$ & \\
\hline Mother with HBV infection & $12(4.08)$ & $5(0.85)$ & 4.96 (1.73 to 14.22$)$ & $4.25(1.11$ to 16.22$) \dagger$ \\
\hline Other members with HBV infection & $45(15.31)$ & $24(4.08)$ & $4.23(2.53$ to 7.13$)$ & $3.64(1.97$ to 6.75$) \dagger$ \\
\hline Family member with liver cirrhosis & $18(6.12)$ & $5(0.85)$ & 7.60 (2.68 to 26.41$)$ & $4.04(1.28$ to 12.78$) \dagger$ \\
\hline Family member with HCC & $11(3.74)$ & $8(1.36)$ & $2.82(1.04$ to 7.76$)$ & \\
\hline Sharing razor & $8(2.72)$ & $6(1.02)$ & $2.71(0.82$ to 9.57$)$ & \\
\hline Sharing towels & $30(10.20)$ & $38(6.46)$ & $1.64(0.97$ to 2.79$)$ & \\
\hline Invasive medical procedure & $103(35.03)$ & $77(13.10)$ & $3.56(2.55$ to 5.02$)$ & $3.72(2.55 \text { to } 5.42)^{*}$ \\
\hline Surgery & $12(4.08)$ & $9(1.53)$ & $2.74(1.06$ to 7.14$)$ & \\
\hline Endoscopy & $10(3.40)$ & $7(1.19)$ & $2.92(1.01$ to 8.60$)$ & \\
\hline Intravenous injection or infusion & $78(26.53)$ & $56(9.52)$ & $3.43(2.31$ to 5.10$)$ & $2.53(1.52$ to 4.21$) \dagger$ \\
\hline Intramuscular injection & $61(20.75)$ & $40(6.80)$ & $3.59(2.29$ to 5.62$)$ & $2.17(1.22$ to 3.84$) \dagger$ \\
\hline Body care and beauty treatments in public places & $130(44.22)$ & $155(26.36)$ & 2.21 (1.65 to 2.97$)$ & $1.52(1.09 \text { to } 2.12)^{*}$ \\
\hline Barber shop shaving ( $\geqslant 4$ times) & $58(19.73)$ & $76(12.93)$ & $1.66(1.12$ to 2.45$)$ & \\
\hline Receiving pedicure in the bath centre & $103(35.03)$ & $102(17.35)$ & $2.55(1.85$ to 3.51$)$ & $1.98(1.36$ to 2.87$) \dagger$ \\
\hline No & 191 & 486 & & \\
\hline Once & 31 & 50 & $1.58(0.95$ to 2.61$)$ & \\
\hline Two to three times & 21 & 28 & 1.91 (1.02 to 3.57$)$ & \\
\hline Four times or more & 51 & 24 & 5.41 (3.15 to 9.33$)$ & \\
\hline Eating out (twice or more/week) & $93(31.63)$ & $69(11.73)$ & $3.48(2.41$ to 5.02$)$ & $3.20(2.14 \text { to } 4.77)^{*}$ \\
\hline Lack of HBV vaccination & $285(96.94)$ & $484(82.31)$ & $6.80(3.28$ to 14.62$)$ & $7.78(3.76 \text { to } 16.11)^{*}$ \\
\hline
\end{tabular}

Data are expressed as number (\%).

*Variables in the multivariate model included household contact with HBV carriers, invasive medical procedure, body care/beauty treatments in public places, eating out and lack of HBV vaccination.

†Variables in the multivariate model included mother with HBV infection, other members with HBV infection, family members with liver cirrhosis, intravenous injection or infusion, intramuscular injection, receiving pedicure in the bath centre, eating out, and absent HBV vaccination.

$\mathrm{AOR}$, adjusted odds ratio; $\mathrm{Cl}$, confidence interval; $\mathrm{HBV}$, hepatitis $\mathrm{B}$ virus; $\mathrm{HCC}$, hepatocellular carcinoma; OR, odds ratio. 
excluded because of $\mathrm{HBsAg}$ seropositivity. Of 572 family members of AHB patients, 52 (9.09\%) were found to be $\mathrm{HBsAg}$ seropositive. HBsAg seropositivity in the family members of AHB patients was higher than that of the matched controls $(p=0.028)$. HBV persisted in $25(8.50 \%)$ of the 294 AHB patients. The CONSORT flow diagram is shown in fig 2.

A total of 78 patients with hepatitis A, 30 with hepatitis C, and 147 with hepatitis $\mathrm{E}$ were excluded, respectively. Of these patients, 40 with hepatitis A, 11 with hepatitis $C$, and 110 with hepatitis $\mathrm{E}$ were HBsAg seropositive.

\section{Risk factors for acute hepatitis B}

In the univariate regression analysis, statistically significant ORs were obtained for household contact with chronic hepatitis B $(p<0.001)$, liver cirrhosis $(p<0.001)$, and hepatocellular carcinoma ( $p=0.022)$, undergoing invasive medical procedures including intramuscular injection $(p<0.001)$, intravenous injections or infusions $(p<0.001)$, endoscopy $(p=0.024)$, and surgery $(p=0.019)$, body care and beauty treatment in public places including pedicure four or more times $(p<0.001)$, and barber shop shaving four or more times $(p=0.008)$, eating out twice or more per week $(p<0.001)$, and lack of HBV vaccination $(p<0.001)$ in the patients with AHB (table 1). Piercing and tattooing in women (OR 2.06 (95\% CI 1.11 to 3.81)), bleeding during pedicure (OR 4.29 (95\% CI 1.92 to 8.55$)$ ) were also risk factors for AHB. No associations were suggested with the other reported risk factors, such as dental surgery, acupuncture, haemodialysis, blood transfusion, promiscuous sexual contact, being with a user of injectable drugs.

In multivariate regression analysis, household contact with a person or persons with liver cirrhosis $(p=0.018)$ and chronic hepatitis B $(p<0.001)$, intramuscular injection $(p=0.008)$, intravenous injections or infusions $(p<0.001)$, receipt of pedicure in bath centres $(p<0.001)$, eating out twice or more per week $(p<0.001)$ and lack of HBV vaccination $(p<0.001)$ were independently associated with AHB.

In evaluating potential relationships among eating out and other risk factors, and their impact on AHB, eating out was frequently found to be related to the receipt of pedicure in the bath centres. In the patients with AHB, 53.8\% of those eating out received pedicure in bath centres, while the percentage was only $34.8 \%$ in the controls $(p=0.017)$. As shown in table 2 , receiving pedicure in bath centres after dinner parties played a role in HBV transmission.

\section{Genotype distribution}

Serum samples of 128 patients with AHB were collected from five major hospitals where AHB was diagnosed. Age and gender composition of the 128 patients was similar to the 294 patients involved in this study ( $p>0.05$ for each). Sixty-eight of the 128 patients were genotyped including 33 (22 men, 11 women) with HBV B2 and 35 (33 men, two women) with HBV C2. In acute

Table 2 Effect of eating out and receiving pedicure services in the bath centres on acute hepatitis B

\begin{tabular}{llrrl}
\hline Eating out & Pedicure & \multicolumn{1}{l}{ Cases } & Controls & OR (95\% CI) \\
\hline No & No & $148(50.3)$ & $439(74.6)$ & \\
& Yes & $53(18.1)$ & $80(13.6)$ & $1.97(1.70$ to 2.97$)$ \\
Yes & No & $43(14.6)$ & $45(7.7)$ & $2.83(1.75$ to 4.59$)$ \\
& Yes & $50(17.0)$ & $24(4.1)$ & $6.18(3.59$ to 10.84$)$ \\
\hline
\end{tabular}

Data are given as the number (\%). $\mathrm{Cl}$, confidence interval; OR, odds ratio.
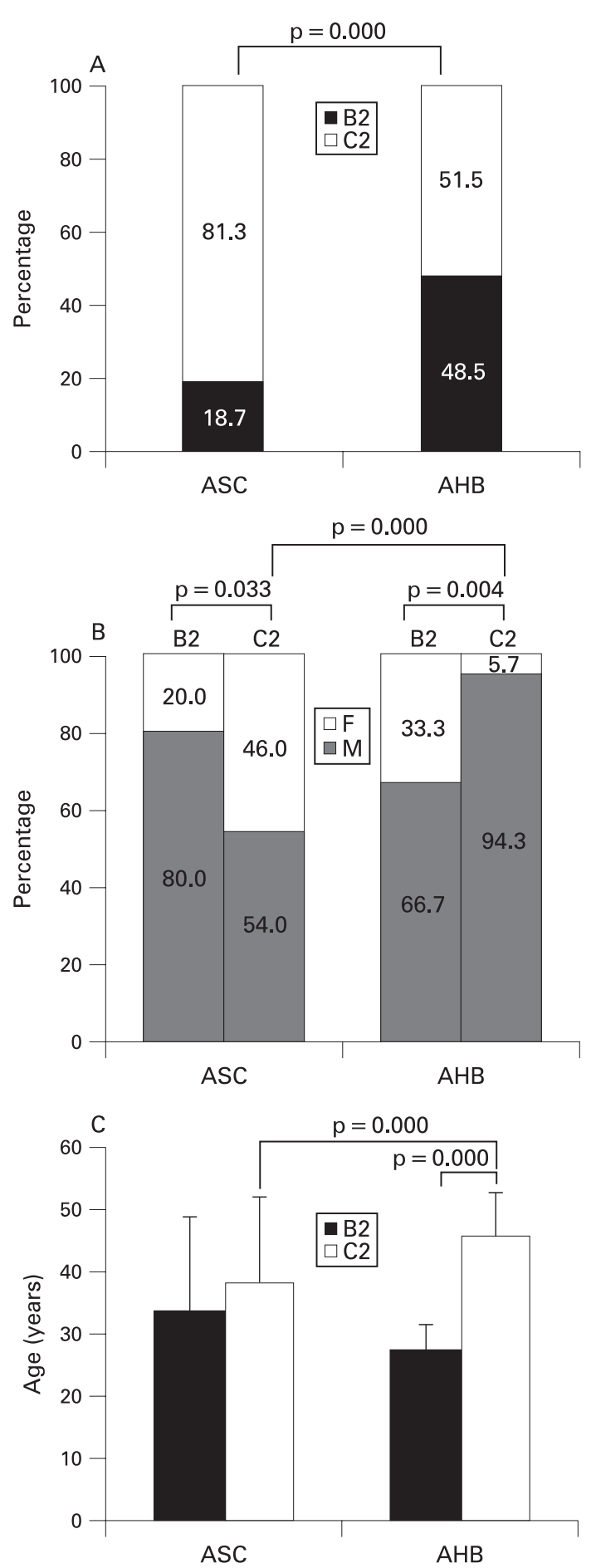

Figure 3 Distributions of genotypes $(A)$, gender $(B)$, and age (C) between 68 patients with acute hepatitis $B(A H B)$ and 107 neighbourhood asymptomatic $\mathrm{HBsAg}$ carriers (ASCs). Age data were expressed as mean with the SD. B2, hepatitis B virus B2; $C 2$, hepatitis $B$ virus $\mathrm{C} 2 ; \mathrm{F}$, female; $\mathrm{M}$, male.

resolving hepatitis $\mathrm{B}$, the serum viral load usually declines rapidly due to vigorous immune response. ${ }^{25}$ Seven (two with HBV B2, five with HBV C2) of the 68 patients progressed into chronic infection. HBV genotypes were determined in 107 of the 113 neighbourhood ASCs The proportion of HBV B2 was significantly higher in the patients with AHB than in ASC (fig 3A). The proportion of women in AHB patients with HBV 
Table 3 Univariate and multivariate regression analyses of the risk factors for chronicification of acute hepatitis B in the patients with hepatitis B virus (HBV) genotyped

\begin{tabular}{|c|c|c|c|c|}
\hline & $\begin{array}{l}\text { Progression to } \\
\text { infection* }\end{array}$ & $\begin{array}{l}\text { Without } \\
\text { progression } \dagger\end{array}$ & OR (95\% Cl) & AOR $(95 \% \mathrm{Cl})$ \\
\hline \multicolumn{5}{|l|}{ Sex } \\
\hline Male & 19 & 50 & & \\
\hline Female & 6 & 11 & $1.44(0.47$ to 4.43$)$ & $2.61(0.71$ to 9.58$)$ \\
\hline \multicolumn{5}{|l|}{ Age (years) } \\
\hline$\leqslant 40$ & 11 & 36 & & \\
\hline$>40$ & 14 & 25 & $1.83(0.72$ to 4.69$)$ & 0.66 (0.19 to 2.23$)$ \\
\hline \multicolumn{5}{|l|}{ Genotype } \\
\hline B2 & 5 & 31 & & \\
\hline C2 & 20 & 30 & $4.13(1.37$ to 12.43$)$ & 6.97 (1.59 to 30.63$)$ \\
\hline
\end{tabular}

*Progression to chronic HBV infection $(n=25)$. $†$ Without chronic HBV progression $(n=61)$

$\mathrm{AOR}$, adjusted odds ratio; $\mathrm{Cl}$, confidence interval; $\mathrm{OR}$, odds ratio.

B2 was significantly higher than in those with HBV C2, while the proportion of men in the neighbourhood ASCs with HBV B2 was significantly higher than in those with HBV C2 (fig 3B). Furthermore, the patients with HBV B2 were significantly younger than those with HBV C2 (27.23 (SD 4.28) vs 45.69 (SD 7.02) years, $p<0.001$ ) (fig $3 C$ ). It is inferred that HBV B2 is transmitted from men to women by sexual activity.

Twenty-five (20 with HBV C2, five with HBV B2) of the 294 patients progressed to chronic infection. The patients with HBV C2 developed chronic infection significantly more often than those infected with HBV B2 $(p=0.013)$. In multivariate analysis, 25 patients who progressed to chronic infection were compared with $61 \mathrm{HBV}$-genotyped patients who had not progressed to chronic infection, HBV C2 was found to be a unique independent factor for the chronicification after adjustments with age and sex (table 3 ).

\section{Serum viral load and $\mathrm{HBeAg}$ status}

Because sera from the patients with AHB did not suffice for all assays, serum viral load from only one-third of the samples was tested by quantitative PCR. The viral loads varied dramatically. Constant serum viral load was determined in 107 of the 113 ASCs. Serum viral load (6.40 (SD 1.82) $\log _{10}$ copies/ml) in ASCs with HBV B2 was significantly higher than the viral load (4.89 (SD 2.13) $\log _{10}$ copies/ml) in ASCs with HBV C2 (fig 4A).

In the $68 \mathrm{AHB}$ patients with HBV genotyped, no difference in seropositivity of $\mathrm{HBeAg}$ was determined between the patients with HBV B2 (39.39\%) and those with HBV C2 (34.29\%). In the 25 patients who progressed to chronic infection, seropositivity of $\mathrm{HBeAg}$ was $45 \%$ and $80 \%$ in those with HBV C2 and HBV $\mathrm{B} 2$, respectively. No statistical differences in seropositivities of $\mathrm{HBeAg}$ were determined between $\mathrm{AHB}$ patients and those who progressed to chronic infection, neither in those with HBV B2 nor in those with HBV C2. However, seropositivity of HBeAg in the neighbourhood ASC with HBV B2 (70.00\%) was significantly higher than that in those with HBV C2 (37.93\%) (fig 4B).

\section{Phylogenetic relationship of HBV intrafamilial transmission}

In preliminary phylogenetic analysis, household contact with HBV infectants might be supported by corresponding phylogenetic clusters (data not shown). Phylogenetic analysis was then used to determine intrafamilial transmission. Of the $68 \mathrm{AHB}$ patients, eight cases (index: family 1) and their available family members seropositive for $\mathrm{HBsAg}$ were included in this assay. Distinct clusters of HBV C2, but not HBV B2, were defined at the family level, including families 2, 5 and 6 and maybe 1 and 8 (fig 5). HBV B2 was identified in the index case of family 4, while this HBsAg positive family member was HBV C1. Thus, household transmission was frequently identified in patients with HBV C2.

\section{DISCUSSION}

In Shanghai, a developed area of China, residents routinely receive HBV screening. Most adults have been tested for HBV markers and have these results documented in their medical records. In this study, apart from serological and clinical chemistry parameters, medical records were used to discriminate newly acquired $\mathrm{AHB}$ from acute exacerbation of chronic
Figure 4 Comparison of serum viral load (A) and hepatitis $B$ e antigen (HBeAg) seropositivity (B) between 20 asymptomatic $\mathrm{HBsAg}$ carriers (ASCs) with HBV B2 and 87 ASCs with HBV C2. Serum viral load was transformed into a logarithmic function and expressed as mean with the SD. HBsAg, hepatitis B surface antigen; HBV, hepatitis $B$ virus.
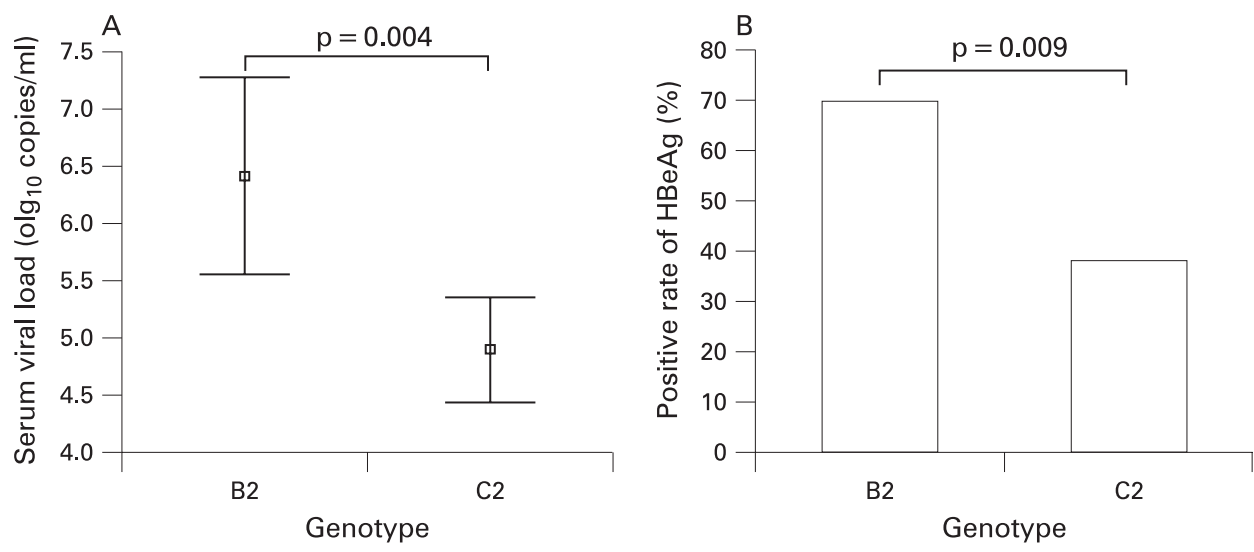
Figure 5 Phylogenetic analysis of the preS and $S$ region of hepatitis $B$ virus (HBV) in eight families (families 1-8) with an index acute hepatitis $B$ (family 1 ) and the family members. The phylogenetic tree was constructed by using the neighbour-joining component of the MEGA 4.0 computer program. Bootstrap values are shown along each main branch. The sequences of HBV preS and S region obtained from the GenBank database were compared with the same region of $\mathrm{HBV}$ isolated in this study. The length of the horizontal bars indicates the number of nucleotide substitutions per site.

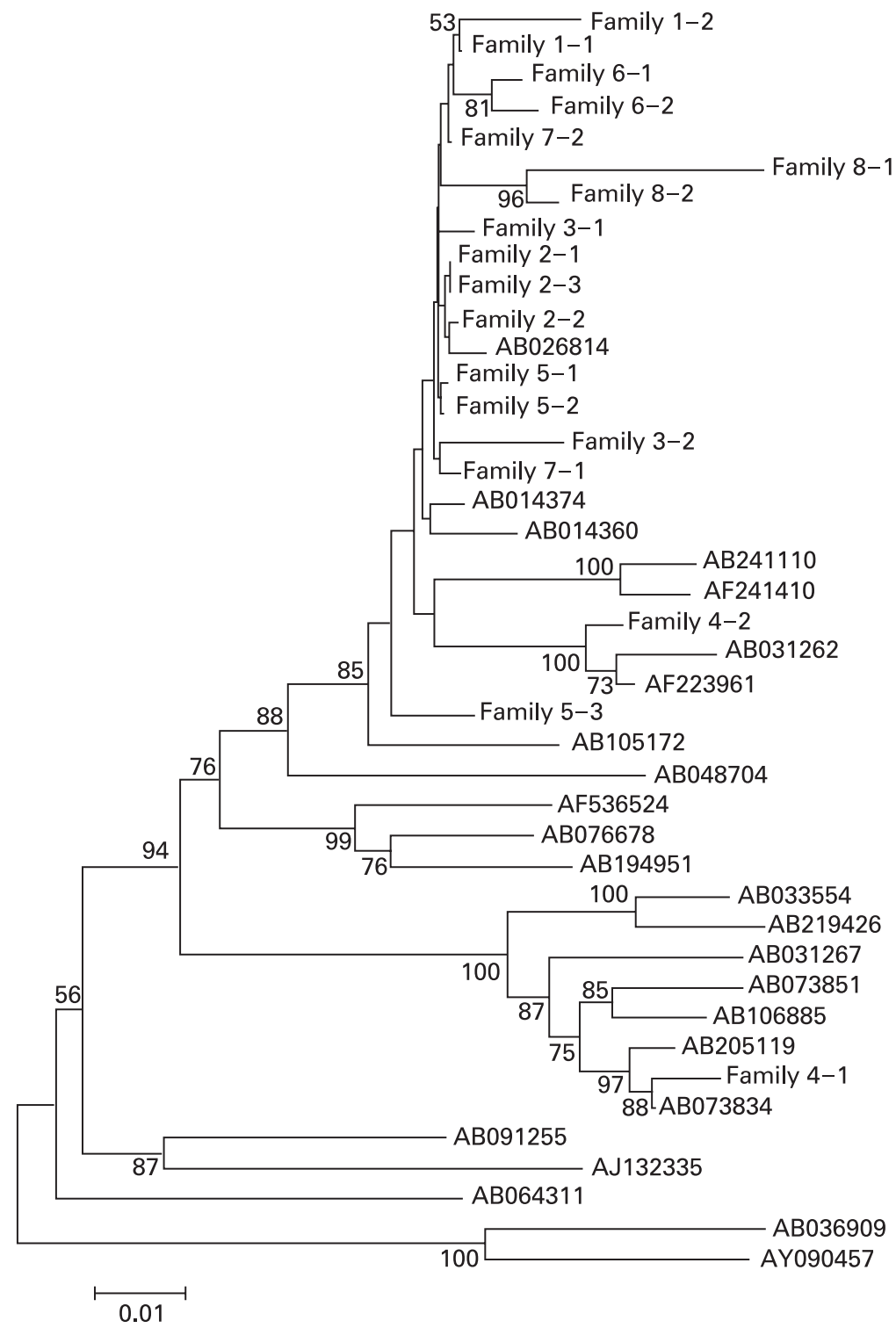

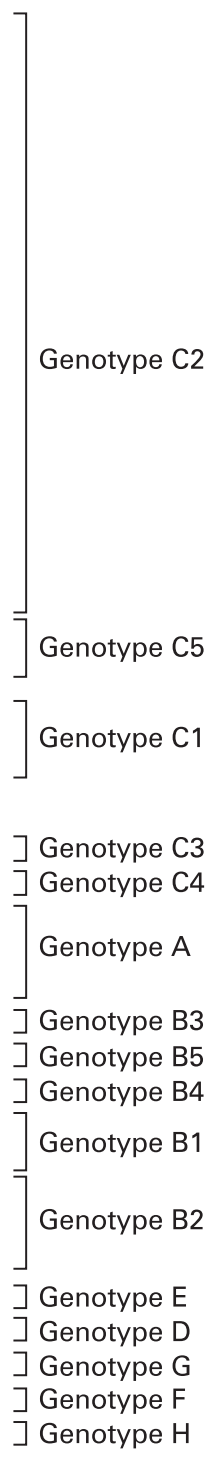

infection. The patients who did not have clear medical records were excluded. Controls were randomly recruited from the source population from which the cases arose, and matched to the cases by sex and date of birth. Controls were obtained without regard to exposure. To promote participation, standard $\mathrm{HBV}$ vaccination was given to those seronegative for $\mathrm{HBs} \mathrm{Ag}$. A pilot study had been carried out to estimate the sample sizes. This case-control study is reliable.

Undergoing invasive medical procedure, receiving body care and beauty treatments in public places, household contact with $\mathrm{HBV}$-associated diseases and lack of $\mathrm{HBV}$ vaccination were current risk factors for adult AHB. The enforced use of disposable syringes for injection has been in place for many years in China. During the survey, we observed that nurses usually did not change their gloves when giving injections or changing bandages after surgery between patients, especially in primary hospitals. These unsatisfactory procedures may contribute to nosocomial transmission of HBV.

Among these risk factors, receiving pedicures in bath centres was emerging. Recently, bath centres which provide pedicure and even hidden sex services have been developing. The health condition of the service professionals and the disinfection situation of the instruments used for the invasive procedures are usually not controlled by local public health agencies. The potential for transmission of infectious diseases exists when receiving manicures and pedicures in urban settings. ${ }^{26}$ Surprisingly, the frequency of eating out was found to be an independent risk factor for AHB. An association of $\mathrm{HBV}$ transmission with the consumption of raw seafood has been reported in Korea. ${ }^{27}$ In this present study, we demonstrated that eating out may be an indicator of other exposure-prone behaviours rather than an actual risk factor for AHB (table 2). In China, promiscuous sexual contact is considered immoral and drug injection is illegal. Some participants refused to provide information concerning promiscuous sexual contact or being users of injectable drugs or cohabiting with drug users, resulting in a probable underestimation of these exposures.

In this study, $8.50 \%$ of the patients with $\mathrm{AHB}$ progressed to chronic infection. Other studies reported rates of $0.2 \%$ in Greece, $1 \%$ in Japan, $2.7 \%$ in Taiwan, $10.4 \%$ in Alaskan Inuit, and $8.1 \%$ or $12.1 \%$ in Germany. ${ }^{18}{ }^{28-32}$ We found different rates of $\mathrm{HBV} B 2$ and $\mathrm{HBV} \mathrm{C} 2$ in $\mathrm{AHB}$ and ASC (fig $3 \mathrm{~A}$ ). In ASCs, $81.3 \%$ was HBV C2 and $18.7 \%$ was HBV B2. The rates were very similar to the figures reported already for chronic $\mathrm{HBV}$ 
patients in this area. ${ }^{33}$ The key result of this study is that HBV C2 was more prone to chronic progression than HBV B2. Gender and age may be determinants of the chronicification because the patients with HBV C2 were much more likely to be older men (fig $3 \mathrm{C}$ ). In multivariate analysis, HBV C2 was confirmed to be an independent factor for AHB chronicity, while gender and age was not (table 3). Although we did not find any difference in viral load and $\mathrm{HBeAg}$ status between the patients with HBV B2 and those with HBV C2, these differences between the neighbourhood ASC with HBV B2 and those with HBV C2 were apparent (fig 4). High concentrations of HBV DNA were found in saliva, semen, nasopharyngeal fluid, urine and tears of ASCs with high viral load, ${ }^{34-36}$ indicating that exposure to these fluids may lead to infection. The higher virus load may have contributed to the more frequent transmission of HBV B2. However, it did not cause a higher rate of chronicity. Higher rate of persistence was not due to higher viral DNA concentrations of HBV C2 in ASC, in contrast to HBV B2 (fig 4A). HBeAg is involved in evading the immune response. ${ }^{37}$ 38 Thus, HBeAg expression was expected to be associated with transition to chronicity. Surprisingly, there were no differences in $\mathrm{HBeAg}$ expression in our AHB patients with or without resolution for both HBV B2 and HBV C2. Thus, the only factor identified as a risk factor for chronicification of AHB in our study remains HBV C2.

Interestingly, $\mathrm{AHB}$ patients with $\mathrm{HBV}$ B2 were much younger, with a higher proportion of women than those with HBV C2. ASC with HBV B2 showed a higher viral load, higher HBeAg status, and higher proportion in men than those with HBV C2. This molecular evidence indicates that heterosexual activity was the most likely transmission route of HBV B2 although this risk factor was not revealed by the field epidemiological study.

Phylogenetic analysis showed that distinct clusters of HBV C2 were defined at the family level. Household contact with HBV-positive family members is one of the most likely transmission routes of $\mathrm{HBV}$ C2. Interestingly, we found a family member with HBV C1, which is frequently found in southern China. In Shanghai and its surrounding area, HBV C1 is very rare. ${ }^{15}$

Major risk factors suggested in this study should be useful in conducting public health interventions for the prevention and control of AHB. If we take into account all the data from this study, an important academic conclusion is that there are inherent - as yet unknown - properties encoded in HBV C2 that lead to higher persistence after acute infection. The identification of the properties of HBV C2 that lead to immune evasion may improve our understanding of the viral life cycle and enable strategies to break immune tolerance induced by HBV.

Acknowledgements: We are grateful to Dr W-H Gerlich (Justus-Liebig University of Giessen, Germany) for critical reading of this manuscript. We acknowledge the team directly involved in the epidemiological survey: Dr Q-H Zhang, Dr W-X Dou, Dr Y-F Shen, Dr Y-C Le and Dr H-M Xu (Centers for Disease Prevention and Control of Songjiang, Baoshan, Pudong, Minhang, and Nanhui administrative districts of Shanghai, respectively).

Funding: This study was financially supported by grants 2004BA718B01 and 04J008 from the Ministry of Science and Technology, China.

Competing interests: None.

Ethics approval: The study protocol conformed to the 1975 Declaration of Helsinki, and was approved by the Institutional Review Boards of Second Military Medical University and Center of Diseases Prevention and Control of Shanghai on 16 January 2004.

\section{REFERENCES}

1. Lavanchy D. Worldwide epidemiology of HBV infection, disease burden, and vaccine prevention. J Clin Virol 2005;34(Suppl 1):S1-3.

2. Custer B, Sullivan SD, Hazlet TK, et al. Global epidemiology of hepatitis B virus. J Clin Gastroenterol 2004;38(10 Suppl):S158-68.

3. Hwang LY, Kramer JR, Troisi C, et al. Relationship of cosmetic procedures and drug use to hepatitis $C$ and hepatitis $B$ virus infections in a low-risk population. Hepatology 2006:44:341-51.

4. Fisker $\mathbf{N}$, Pedersen $\mathrm{C}$, Lange $\mathrm{M}$, et al. Molecular epidemiology of hepatitis $\mathrm{B}$ virus infections in Denmark. J Clin Virol 2004;31:46-52.

5. Redd JT, Baumbach J, Kohn W, et al. Patient-to-patient transmission of hepatitis B virus associated with oral surgery. J Infect Dis 2007;195:1311-4.

6. Yao GB. Importance of perinatal versus horizontal transmission of hepatitis B virus infection in China. Gut 1996;38(Suppl 2):S39-42.

7. Thio CL, Thomas DL, Karacki $P$, et al. Comprehensive analysis of class I and class II HLA antigens and chronic hepatitis B virus infection. J Virol 2003;77:12083-7.

8. Deng G, Zhou G, Zhai $Y$, et al. Association of estrogen receptor alpha polymorphisms with susceptibility to chronic hepatitis B virus infection. Hepatology 2004;40:318-26.

9. Chu CJ, Lok AS. Clinical significance of hepatitis B virus genotypes. Hepatology 2002;35:1274-6.

10. Kramvis A, Kew M, Francois G. Hepatitis B virus genotypes. Vaccine 2005;23:2409-23

11. Schaefer S. Hepatitis B virus - significance of genotypes. J Viral Hepatol 2005;12:111-24.

12. Miyakawa $\mathbf{Y}$, Mizokami M. Classifying hepatitis B virus genotypes. Intervirology 2003:46:329-38.

13. Norder $\mathbf{H}$, Couroucé AM, Coursaget $P$, et al. Genetic diversity of hepatitis B virus strains derived worldwide: genotypes, subgenotypes, and HBsAg subtypes. Intervirology 2004;47:289-309.

14. Schaefer S. Hepatitis B virus taxonomy and hepatitis B virus genotypes. World J Gastroenterol 2007;13:14-21.

15. Yin J, Zhang H, Li C, et al. Role of hepatitis B virus genotype mixture subgenotypes C2 and B2 on hepatocellular carcinoma: compared with chronic hepatitis B and asymptomatic carrier state in the same area. Carcinogenesis 2008;29:1685-91.

16. Mayerat C, Mantegani A, Frei PC. Does hepatitis B virus (HBV) genotype influence the clinical outcome of HBV infection? J Viral Hepatol 1999;6:299-304.

17. Wai CT, Fontana RJ, Polson J, et al. Clinical outcome and virological characteristics of hepatitis B-related acute liver failure in the United States. J Viral Hepatol 2005:12:192-8

18. Ozasa A, Tanaka $Y$, Orito $E$, et al. Influence of genotypes and precore mutations on fulminant or chronic outcome of acute hepatitis B virus infection. Hepatology 2006:44:326-34.

19. Barker LF, Chisari FV, McGrath PP, et al. Transmission of viral hepatitis type B to chimpanzees. J Infect Dis 1973;127:648-62.

20. Cote PJ, Korba BE, Miller RH, et al. Effects of age and viral determinants on chronicity as an outcome of experimental woodchuck hepatitis virus infection. Hepatology 2000;31:190-200.

21. Fong TL, Di Bisceglie AM, Biswas $R$, et al. High levels of viral replication during acute hepatitis B infection predict progression to chronicity. J Med Virol 1994; $43: 155-8$

22. Lok AS, McMahon BJ. Chronic hepatitis B. Hepatology 2007;45: 507-39.

23. Chen J, Yin J, Tan X, et al. Improved multiplex-PCR to identify HBV genotypes A-F and subgenotypes B1, B2 and C1, C2. J Clin Virol 2007;38:238-43.

24. Tamura K, Dudley J, Nei M, et al. MEGA4: Molecular Evolutionary Genetics Analysis (MEGA) software version 4.0. Mol Biol Evol 2007;24:1596-9.

25. Chulanov VP, Shipulin GA, Schaefer S, et al. Kinetics of HBV DNA and HBsAg in acute hepatitis B patients with and without coinfection by other hepatitis viruses. J Med Virol 2003;69:313-23.

26. Johnson IL, Dwyer JJ, Rusen ID, et al. Survey of infection control procedures at manicure and pedicure establishments in North York. Can J Public Health 2001;:92:134-7.

27. Lee $\mathbf{D H}, \mathrm{Kim} \mathrm{JH}, \mathrm{Nam} \mathrm{JJ}$, et al. Epidemiological findings of hepatitis B infection based on 1998 National Health and Nutrition Survey in Korea. J Korean Med Sci 2002;17:457-62.

28. Tassopoulos NC, Papaevangelou GJ, Sjogren MH, et al. Natural history of acute hepatitis B surface antigen-positive hepatitis in Greek adults. Gastroenterology 1987:92:1844-50.

29. Beasley RP, Hwang LY, Lin CC, et al. Incidence of hepatitis among students at a university in Taiwan. Am J Epidemiol 1983;117:213-22.

30. McMahon BJ, Alward WL, Hall DB, et al. Acute hepatitis B virus infection: relation of age to the clinical expression of disease and subsequent development of the carrier state. J Infect Dis 1985;151:599-603.

31. Kaboth U, Adami B, Alexander M, et al. Cooperative prospective study "acute viral hepatitis" (In German). Verh Dtsch Ges Inn Med 1980;86:749-56.

32. Schomerus $\mathbf{H}$, Wiedmann KH, Dolle W, et al. (+)-Cyanidanol-3 in the treatment of acute viral hepatitis: a randomized controlled trial. Hepatology 1984;4:331-5.

33. Ding $\mathbf{X}$, Mizokami $\mathbf{M}, \mathrm{Yao}_{\mathrm{G}} \mathrm{G}$, et al. Hepatitis $\mathrm{B}$ virus genotype distribution among chronic hepatitis B virus carriers in Shanghai, China. Intervirology 2001;44:43-7.

34. Kidd-Ljunggren $\mathbf{K}$, Holmberg A, Bläckberg J, et al. High levels of hepatitis B virus DNA in body fluids from chronic carriers. J Hosp Infect 2006;64:352-7. 
35. Hui AY, Hung LC, Tse PC, et al. Transmission of hepatitis B by human bite confirmation by detection of virus in saliva and full genome sequencing. J Clin Virol 2005;33:254-6.

36. Jenison SA, Lemon SM, Baker LN, et al. Quantitative analysis of hepatitis B virus DNA in saliva and semen of chronically infected homosexual men. $J$ Infect Dis 1987; 156:299-307.
37. Chen $\mathbf{M}$, Sallberg $\mathbf{M}$, Hughes J, et al. Immune tolerance split between hepatitis B virus precore and core proteins. J Virol 2005:79:3016-27.

38. Yuen MF, Wong DK, Zheng BJ, et al. Difference in $T$ helper responses during hepatitis flares in hepatitis $\mathrm{B}$ e antigen (HBeAg)-positive patients with genotypes $\mathrm{B}$ and $\mathrm{C}$ : implication for early $\mathrm{HBeAg}$ seroconversion. J Viral Hepatol 2007:14:269-75

\section{Editor's quiz: GI snapshot}

\section{ANSWER}

From the question on page 1665

Colocutaneous fistula is a rare complication of percutaneous endoscopic gastrostomy (PEG) tube placement. ${ }^{12}$ In this case, the injection of water-soluble contrast medium via the PEG tube caused opacification of the transverse colon, and the contrast medium passed smoothly to the distal colon (fig 1 of the question). Subsequent CT scan showed the tip of the feeding tube in the lumen of the mid-transverse colon (fig 2). The PEG tube was withdrawn from the transverse colon using colonoscopy (fig 1A), and the hole was sealed with haemoclips (fig 1B).

Faecal material in a PEG tube and diarrhoea after feeding are two signs that should alert clinicians to the possibility of PEG tube misplacement into the colon. ${ }^{3}$ Two possible mechanisms have been proposed for colocutaneous fistula. ${ }^{3}$ One is the formation of gastrocolic fistula. During the initial procedure of PEG tube insertion, the needle passes through a segment of colon (especially in the transverse colon) before it enters the stomach. Then, the tube dislodges into the colon. The other mechanism is due to the erosions of the gastric wall into the colon caused by the pressure of the tube bumper. In the cases of previous abdominal surgery, clinical history of megacolon as well as subphrenic transposition of the colon, doctors should keep a high index of suspicion to avoid transcolonic insertion of the needle. ${ }^{3}$

Careful endoscopic technique with trans-illumination is mandatory when placing a PEG tube. It is crucial to avoid insufflating large amounts of air into the stomach during the procedure, as it can cause gastric rotation and pull transverse colon into the stomach. ${ }^{2}{ }^{3}$ In addition, the direct endoscopic observation of the imprint of a finger pressed on the skin and the absence of any air aspirated through a small-gauge anesthetic needle during insertion are also fundamental to ensure the percutaneous puncture does not pass through the colon and risk creating a colocutaneous fistula. ${ }^{3}$

Gut 2008;57:1720. doi:10.1136/gut.2008.158410a

\section{REFERENCES}

1. Smyth GP, McGreal GT, McDermott EW. Delayed presentation of a gastric coloncutaneous fistula after percutaneous fluoroscopic gastrostomy. Nutrition 2003:19:905-6.

2. Huang SY, Levine MS, Raper SE. Gastrocolic fistula with migration of feeding tube into transverse colon as a complication of percutaneous endoscopic gastrostomy. Am J Roentgenol 2005;184(Suppl 3):S65-6.

3. Friedmann R, Feldman H, Sonnenblick M. Misplacement of percutaneously inserted gastrostomy tube into the colon: report of 6 cases and review of the literature. J Parenter Enteral Nutri 2007;31:469-76.
Figure 1 (A) A colonoscopic view of the transverse colon. (B) The hole is sealed with haemoclips.
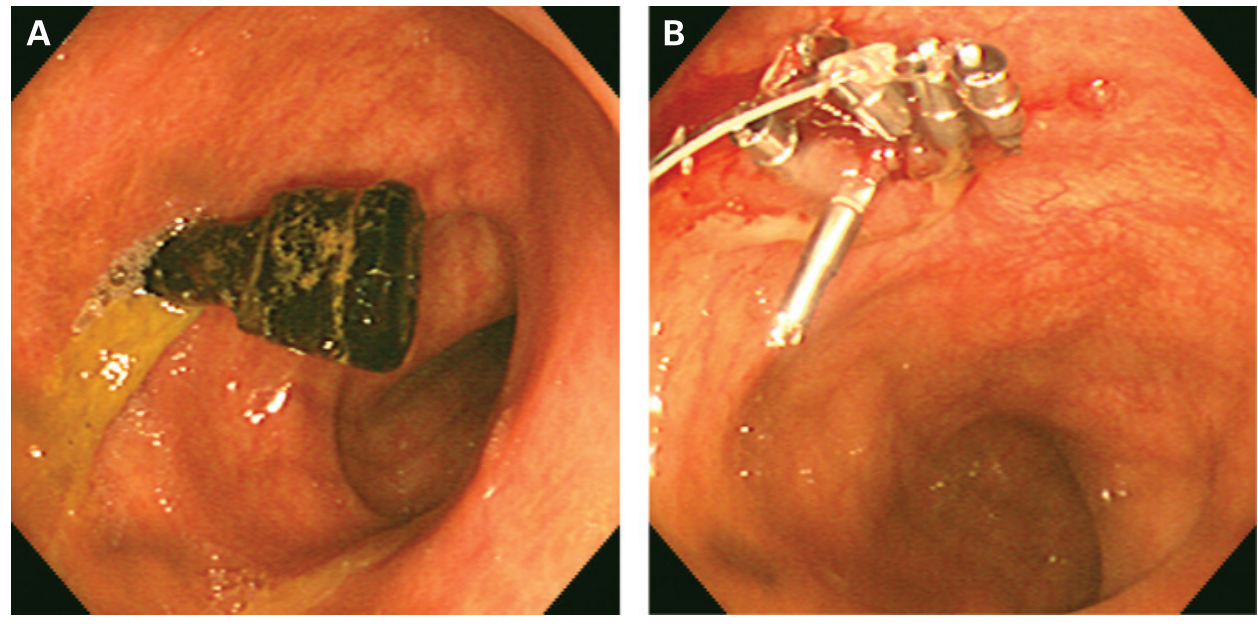